\title{
ALIF
}

URL: $\underline{\text { https://alif.live }}$

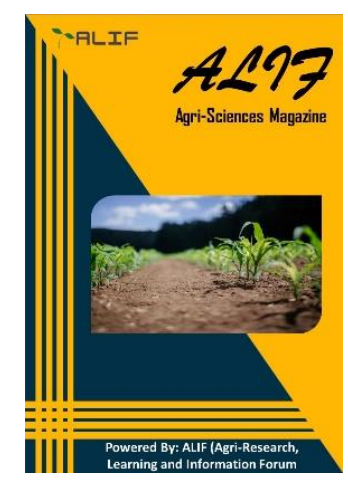

\section{Agriculture and food security}

\author{
Najma Majeed ${ }^{* 1}$
}

${ }^{1}$ Department of Soil \& Environmental Science, Muhammad Nawaz Shareef University of Agriculture, Multan

URL: alif.live/10-5281-zenodo-5816990/

DOI: doi.org/ 10.5281/zenodo.5816990

\begin{tabular}{l|l|l}
\hline Received: Jan 01, 2022 & Published: Jan 04, 2022 & Issue: 3. Food Security \\
\hline
\end{tabular}

Agriculture is a human activity of man which is carried out essentially to produce food, feed, and fiber by the premeditated and controlled use of Animals and Plants. Agricultural is a way of life, a cultural practice with all the inference of the word culture. They consist of growing crops with local seeds, relishing vegetables, fruits of their kind and quality, caring for animals that have adapted to the environment. In its true sense, it is ecological agriculture.

Agriculture is considered the backbone of Pakistan's economy. According to the Economic Survey of Pakistan 2001-2002, nearly one-fourth of the total output of the GDP and 44 percent of total employment is produced in agriculture. Greater than 67 percent of the country's rural population is directly or indirectly associated with agriculture for their income/work. The role of agriculture is most important in dwelling the issue of food security in low-income countries like Pakistan. Agriculture should be suitable for lining population growth and annihilating poverty and hunger, which are the terminal causes of food insecurity.

Out of 155 million populations in Pakistan, 35 million people are malnutrition. As productivity growth is deficient in meeting adequate demand in much of the developing world, net food implications are expected to increase incomparably for developing countries. As the growth rate of Pakistan is increasing
$2.1 \%$ annum, therefore, the production of food is increasing, and the percentage share of the agriculture sector in total GDP has increased up to $25 \%$ since 2000. However, according to the economic survey of 2009 2010, agriculture sectors contribute $21 \%$ of GDP and absorb $45 \%$ of the country's labor force.

Food security exists when all people have a physical, social, economic approach to adequate safe and nutritious food that meets their dietary needs and food prepossession for an active and healthy life. The quality of food assessable to the masses is essential as well. Thus, apart from assurance of food, the question of food security also means distant and quality food for healthy lives. In the present time, the pressing challenge is to produce more food and ensure food security regionally in order to control poverty and undernourishment and, at the same time to improve human health and welfare. Although poverty and undernourishment are increasing in large cities, $80 \%$ of the undernourished and poor live in rural areas in the long term as the topmost world extension of cereal grains is estimated at $3300 \mathrm{Mt} 60 \%$ more than today (Gilland 2002). The potentiality to produce cereal grains and animal protein may be leveling off immediately. Therefore, the gully between the amount of food produced and the global population to feed is believable to increase until 2050 .

*Correspondence: 2018-uam-398@mnsuam.edu.pk 
Nowadays, the problem of food insecurity is a traditional fact for almost every country of the world, as more than 800 million people are malnourished around the globe. Consequently, persistent residues of these chemicals contaminate food and are scattered in the environment. Correlated efforts are needed to increase the production of food but to increase food quality and safety and control residues of persistent pesticides in the environment. Pakistan has ranked 11th faced the threat of food insecurity among other countries.

\section{Factors affecting food security}

The global food supply is not even. Some places produce more food than others. Soil quality, gradient, and Climate are the physical factors. Human factors (technology) have historically controlled the quantity and type of food produced in any location. Some other factors include loss of farmland, pests, diseases, water stress conflicts, and poverty.

Safe production and secure food contribution are some of the significant demands of low-income countries - an approach for controlling the agricultural landscape to ensure sustainability and food security in the 21st Century. The increasing human population in developing countries, specifically Pakistan, increases the pressure on food production and utilization. Therefore, stress on the agriculture ecosystem is increased compared to the past to fulfill the population's demands. Different Agriculture practices have different impacts on agriculture production and ecosystem services.

Water and land are essential natural resources for humankind. The application for food, fiber, and shelter increases with the continuous increase in the world's population. The active urbanization, continuous tillage, and greater use of fertilizers, pesticides, and fossil fuels pollute natural resources and the environment. The better use of cultivars, more provocative to diseases and allowing for higher yields, seems to be a more advisable pathway to contribute to food security. Another way of better food security is by increasing foodstuff's shelf life through irradiation of foods. The establishment of organic agriculture may enhance food safety but does not help to cope with food security. It will be required to increase agriculture production further.

In less developed and developing countries, reducing post-harvest wheat losses can provide a sustainable solution to food security, improve rural employments, reduce poverty and increase incomes. Agricultural policy focuses on sustainable food security, increasing productivity, encouraging commercial agriculture, encouraging income diversification interventions, and promoting export orientation.

The concern of food security is increasing in developed and developing countries and recommending a wide range of sustainable agriculture practices. The agriculture sector completed a growth rate of $3.1 \%$ during 2011-12. Agriculture still represents $40 \%$ of the employment hiring in Pakistan. An insufficient number of researches observed the relative effect of urban agriculture on sustainable food security, which influences the selection of urban dwellers in Pakistan regarding food choices. Based on consumers' food preferences, this study checks out the direct effects of several urban agriculture determinants on food safety. 